\title{
COVID-19 Pandemisi Döneminde Romatizmal Hastalıklara Halkın İlgisi: Google Trends Verilerinin Analizi
}

\author{
Tuba ERDEM SULTANOĞLU 國, Safinaz ATAOĞLU 國 ${ }^{1}$
}

Öz

Amaç: Çalışmanın amacı Koronavirüs Hastalığı-2019 (COVID-19) pandemisi sırasında romatizmal hastalıklara halkın ilgisini Google Trends verilerinin analizi ile değerlendirmektir.

Gereç ve Yöntemler: Çalışmanın tüm verileri Google arama sayılarının ve ilişkilerinin paylaşıldığı, https://trends.google.com/trends/ aracılığıyla Google Trends veri tabanından elde edildi. Bu çalışma Mart 2019-Mart 2020 (pandemi öncesi dönem) ve Mart 2020-Mart 2021 (pandemi dönemi) arasında yapılan aramaları içermektedir. Google Trends arama terimleri gut, fibromiyalji, ailevi Akdeniz ateşi, Behçet hastalığı, sistemik lupus eritematosus, ankilozan spondilit, romatoid artrit, osteoartrit, sjögren sendromu ve skleroderma olarak belirlendi. Türkiye seçimiyle arama yoğunlaşmaları tüm kategorilerde incelendi.

Bulgular: Çalışmamızda Türkiye'de romatizmal hastalıklara olan dijital ilginin GT verileri karşılaştıııldı. Pandemi öncesi dönem ve pandemi döneminde göreli arama hacmi en fazla olan ilk beş romatizmal hastalığın gut, fibromiyalji, ailevi Akdeniz ateşi, Behçet hastalığ 1 ve sistemik lupus eritematozus olduğu tespit edildi. On arama terimi için ilgili arama hacmi incelendiğinde pandemi döneminde ailesel Akdeniz ateşi, ankilozan spondilit, romatoid artrit ve sjögren sendromu istatistiksel olarak anlamlı derecede azalırken Behçet hastalığı arama terimi anlamlı ölçüde arttı.

Sonuç: COVID-19 gibi pandemilerde çevrim içi internet arama sonuçlarının değerlendirilmesi hem halkın hastalıklara olan ilgisini ve eğilimlerini belirleme hem de toplumsal farkındalığın oluşturulabilmesi açısından önemlidir. Farkındalık günlerinin hastalıkların tanınmasında potansiyel faydalar sağlaması nedeniyle daha fazla vurgulanması gerektiğini düşünmekteyiz.

Anahtar Kelimeler: COVID-19; Google arama trendleri; Türkiye; romatizmal hastalıklar.

\section{Public Interest in Rheumatic Diseases during the COVID-19 Pandemic: Analysis of Google Trends Data}

\section{ABSTRACT}

Aim: The aim of the study is to evaluate the public interest in rheumatic diseases during the Coronavirus Disease-2019 (COVID-19) pandemic by using Google Trends data.

Material and methods: All data of the study were obtained from the Google Trends database via https://trends.google.com/trends/, where Google search numbers and relationships are shared. This study contains the searches made between March 2019-March 2020 (pre-pandemic period) and March 2020-March 2021 (pandemic period). Google Trends search terms were determined as gout, fibromyalgia, familial Mediterranean fever, Behçet's disease, systemic lupus erythematosus, ankylosing spondylitis, rheumatoid arthritis, osteoarthritis, Sjogren's syndrome, and scleroderma. All categories was chosen as subject and Turkey was chosen as the country.

Results: In our study, GT data of digital interest in rheumatic diseases in Turkey were compared. It was determined that the first five rheumatic diseases with the highest relative search volume in the pre-pandemic and pandemic periods were gout, fibromyalgia, familial Mediterranean fever, Behçet's disease and systemic lupus erythematosus. When the relevant search volume for 10 search terms was examined, familial Mediterranean fever, ankylosing spondylitis, rheumatoid arthritis and Sjögren's syndrome decreased statistically during the pandemic period, while the search term for Behçet's disease increased significantly.

Conclusion: Evaluation of online internet search results in pandemics such as COVID-19 is important both in terms of determining the public's interest and tendencies towards diseases and creating social awareness. We think that awareness days should be emphasized more, because it provides potential benefits in the recognition of diseases.

1 Düzce Üniversitesi, Tıp Fakültesi, Fiziksel Tıp ve Rehabilitasyon Anabilim Dalı, Düzce, Türkiye 
Keywords: COVID-19; google trends; Turkey; rheumatic diseases.

\section{GíRiş}

2019 yılının sonunda Çin'in Wuhan kentinde ortaya çıkan ve daha önce insanlarda belirlenmemiş yeni bir koronavirüsün (2019-nCoV) neden olduğu Coronavirüs Hastalığı-2019 [coronavirus disease-2019 (COVID-19)] Dünya Sağlık Örgütü tarafından 11 Mart 2020'de pandemi olarak ilan edildi. Türkiye'de ilk olgu 11 Mart 2020, COVID-19 ile ilişkili ilk ölüm ise 17 Mart 2020 tarihinde görüldü. Pandemi süreci Fiziksel Tip ve Rehabilitasyon (FTR) alanında; hastalığın subakut ve kronik dönemde gerektirebileceği FTR ihtiyac1, telerehabilitasyonun artan değeri, sosyal izolasyonda kas iskelet sistemini hareketsizliğin olumsuz etkilerinden korumaya yönelik önerilerin oluşturulması, romatizmal hastalıkların tedavi sürecindeki devamlılığın takibi, COVID-19 semptomlarını tanıma ve hareket sistemi sorunlarının ayırıcı tanısında yer verme bilincinin oluşması gibi sonuçlar yaratmıştır. Yaşamın birçok alanı, evde kalma uyarılarından sonra büyük ölçüde etkilenmiştir. Romatizmal hastalıklar gibi kronik hastalığ olan hastaların sağlık kurumlarına ulaşamaması tedavi devamlılığında ve hastalıkların takibinde kesintilere neden oldu. Romatizmal hastalıkların tedavisinde kullanılan bazı immünomodülatör ve antiinflamatuvar ilaçlar COVID-19 tedavisinde kullanıldı. Romatizmal hastalığı olan kişilerin altta yatan romatizmal hastalıkları nedeniyle COVID-19 enfeksiyonuna yakalanma risklerinin artmasıyla ilgili endişeleri internet kullanımını arttırıcı bir faktör oldu (1-8).

Günümüzde internet birçok konuda zengin bilgiler sunmakta; dünya genelinde sağlık sorunları ile ilgili bilgileri elde etmek için internet üzerinden arama motorları yaygın olarak kullanılmaktadır. İnsanlar internet araştırmaları ile çözümler aramaktadır. Bu kapsamda Türkiye'de 65,8 milyon $(\% 77,7)$ internet kullanıcısı bulunmakta olup, 2021 yılında Google \%80,5 pazar payı ile en çok tercih edilen arama motorudur $(9,10)$. Toplumun sağlığa ilişkin farkındalıklarının tespitinde internet kullanımı, sağlık çalışanları için de anlamlı bir kaynak haline gelmiştir. İnternet aramaları, insanların ne bilmek istediklerini ve ne zaman bilmek istediklerini gösteren veriler sağlamaktadır. Böylece internet kaynaklı bilgilerin halk sağlığ 1 için kullanılması anlamındaki "dijital epidemiyoloji” ya da "eepidemiyoloji" verileri elde edilmektedir $(11,12)$. Google Trends (GT) Google arama hacimlerinin Web tabanl ücretsiz izleme sistemidir. Aramaların sayısı ve yoğunluğu genel erişime açık haldedir. GT'nin sağlık alanına entegrasyonu ve epidemiyolojik verilerin sağlanması; GT arama hacmi verileriyle hastalıklara olan ilginin belirlenebilmesi çalışmalarda vurgulanmıştır. Sağlık alanında GT verilerinin analizi İnfluenza ve Zika virüsü salgınlarında $(13,14)$; COVID-19 pandemisinde çeşitli sağlık konularında halkın ilgisini değerlendirmek amacıyla kullanılmıştır (16-23).

Çalışmamızın amacı, COVID-19 pandemisi döneminde halkın romatizmal hastalıklara ilgisini incelemek için GT verilerini kullanmaktır.

\section{GEREÇ VE YÖNTEMLER}

Çalışmanın verileri Google arama sayılarının ve ilişkilerinin paylaşıldığı, sık kullanılan arama motorlarından biri olan https://trends.google.com/trends/ aracılığıyla toplandı; romatizmal hastalıklar ile ilgili internette yapılan aramaların eğilimleri incelendi. GT, 2004 yılından itibaren farklı arama terimlerinin zaman içerisinde birbirleriyle kıyaslanmasına olanak sağlayan; aramaların sayısını ve yoğunluğunu, hangi aramaların ne sıklıkla yapıldığını, ücretsiz, herkesin erişebileceği şekilde ve çevrim içi olarak sunar. GT, 0 (arama hacmi en yüksek hacmin <\%1'i) ile 100 (en yüksek popülerlik) arasında bir ölçekte herhangi bir terimle ilgili toplam arama sayısı için verileri algoritmik olarak normalleştirir. $\mathrm{Bu}$ verileri haftalık göreli arama hacmi olarak sunar. Göreli arama hacmi değerleri y ekseninde gösterilir ve en yüksek arama hacmiyle karşılaştırıldığında bir oran gösterir. Göreli arama hacminin 0 olması ise, arama yapılmadığını gösterir $(24,25)$. GT, kelimelerin farklı ülkelerde ve Amerika Birleşik Devletleri'nde eyaletler düzeyinde aranma sıklıklarını gösterebildiğinden çalışmamızda Türkiye seçimiyle arama yoğunlaşmaları değerlendirildi. Verilerin analizinde tarih aralığ 1 pandemi öncesi dönem için Mart 2019-Mart 2020 ve pandemi dönemi için Mart 2020-Mart 2021 olarak belirlendi. Google Trends arama terimleri sik görülen romatizmal hastalıklardan "gut","fibromiyalji”, "ailevi akdeniz ateşi”, "Behçet hastalığı", "sistemik lupus eritematosus", "ankilozan spondilit", "romatoid artrit", "osteoartrit", "sjögren sendromu" ve "skleroderma" olarak belirlenerek tüm kategorilerde incelendi (26). Göreli arama hacminin düşük olması nedeniyle veri elde edilemeyen romatizmal hastalıklar çalışmaya dahil edilemedi. Fibramiyalji farkındalık günü, dünya artrit günü, dünya ailevi Akdeniz ateşi farkındalık günü gibi zaman dilimlerinin Google arama hacminde ani artışlara etkisi araştırıldı. Çalışmanın tüm verileri GT veri tabanından elde edildi ve bu araştırma kapsamında herhangi bir sağlık kurumunda hastalara uygulama yapılmadı.

\section{İstatistiksel Analiz}

Verilerin analizi Windows için SPSS (Statistical Package for Social Sciences) 23.0 versiyon paket programı kullanılarak yapıldı. Normal dağılıma uygunluk Kolmogorov-Smirnov testi ile incelendi. Normal dağılım gösteren parametrelerinin karşılaştırmalarında Student $\mathrm{t}$ testi kullanıldı. $\mathrm{p}<0,05$ değeri, istatistiksel olarak anlamlı kabul edildi.

\section{BULGULAR}

Pandemi öncesi dönem ve pandemi döneminde 10 arama terimi için Türkiye'de romatizmal hastalıklara olan dijital ilginin GT verileri karşılaştırıldığında göreli arama hacmi en fazla olan ilk beş romatizmal hastalığın gut, fibromiyalji, ailevi Akdeniz ateşi, Behçet hastalığı ve sistemik lupus eritematozus olduğu tespit edildi. Göreli arama hacimlerine göre hastalıkların karşılaştırması şekil 1 ve 2 ile gösterildi. 


\section{- Gut - Fibromiyalji - Ailevi Akdeniz ateși - Behçet Hastaliğı \\ - Sistemik Lupus Eritematozus}

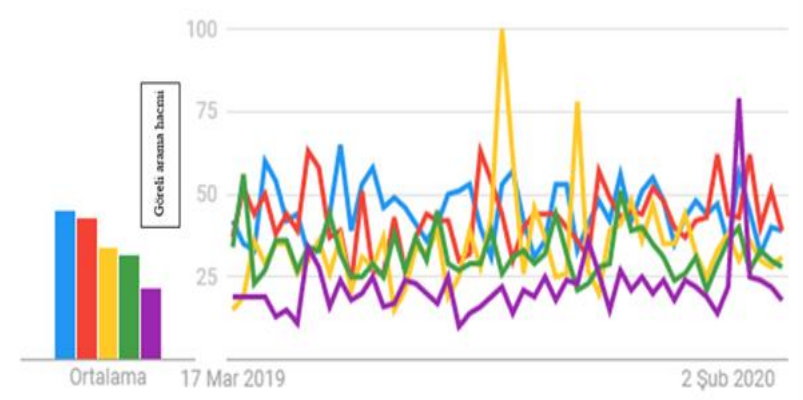

Şekil 1. Mart 2019-Mart 2020 tarihleri arasında Türkiye'de romatizmal hastaliklara olan dijital ilginin karşılaştrılması

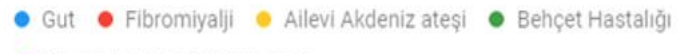

- Sistemik Lupus Eritematozus

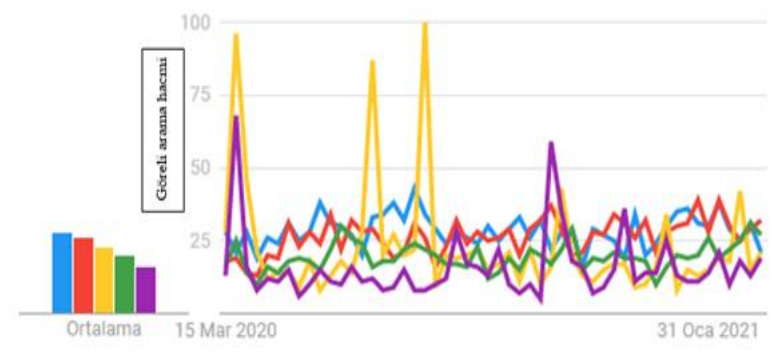

Şekil 2. Mart 2020-Mart 2021 tarihleri arasnda Tưrkiye'de romatizmal hastaliklara olan dijital ilginin karșilasturilması

Pandemi öncesi dönemde ve pandemi döneminde 10 arama terimi için ilgili arama hacmi incelendiğinde ailesel Akdeniz ateşi $(p<0,001)$, ankilozan spondilit $(p<0,001)$, romatoid artrit $(p<0,001)$ ve sjögren sendromunun $(\mathrm{p}=0,012)$ arama hacim ortalamaları, pandemi döneminde, pandemi öncesi döneme göre istatistiksel olarak anlamlı derecede azaldı. Behçet hastalığına ilişkin arama hacim ortalaması ise pandemi döneminde, pandemi öncesi döneme göre istatistiksel olarak anlamlı ölçüde arttı $(\mathrm{p}=0,041)$ (Tablo 1).

Çalışmamızda romatizmal hastalıklarla ilgili farkındalık günlerinin çevrim içi aramalara etkisi incelendi. Dijital ilginin en fazla olduğu romatizmal hastalıklarla ilgili farkındalık günlerine ait göreli arama hacimleri incelendiğinde, pandemi öncesi dönemde sadece ailesel Akdeniz ateşi terimi ile yapılan aramalarda ani artış olduğu saptandı. Pandemi döneminde ise farkındalık günlerinin göreli arama hacmindeki artışlara etkisinin

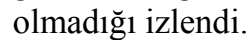

\section{TARTISSMA}

Çalışmamızın amacı; COVID-19 pandemisinde virüsün yayılmasını engellemek için sağlık otoriteleri tarafindan vurgulanan 'evde kal' çağrıları ile hastaların poliklinik başvurularının azaldığı dönemde romatizmal hastalıklara halkın ilgisini GT verilerinin analizi ile değerlendirmekti. 10 arama terimi için Türkiye'de romatizmal hastalıklara olan dijital ilginin GT verileri karşılaştıııldığında göreli
Tablo 1. Romatizmal hastalıkların göreli arama hacmi ortalamalarının karşılaştırılması

\begin{tabular}{|c|c|c|c|c|}
\hline $\begin{array}{l}\text { Romatolojik } \\
\text { Hastalık }\end{array}$ & $\begin{array}{l}\text { Pandemi } \\
\text { öncesi } \\
\text { Göreli } \\
\text { Arama } \\
\text { Hacmi } \\
\text { Ortalamas1 } \\
\text { (Ort. } \pm \text { S.S.) }\end{array}$ & $\begin{array}{l}\text { Pandemi } \\
\text { dönemi } \\
\text { Göreli } \\
\text { Arama } \\
\text { Hacmi } \\
\text { Ortalaması } \\
\text { (Ort. } \pm \text { S.S.) }\end{array}$ & $\begin{array}{l}\% \\
\text { değişiklik }\end{array}$ & $\mathrm{p}$ \\
\hline Gut & $68,64 \pm 12,9$ & $65,37 \pm 12,78$ & $-4,7$ & 0,214 \\
\hline Fibromiyalji & $68 \pm 14,94$ & $67,81 \pm 15,39$ & $-0,2$ & 0,945 \\
\hline $\begin{array}{l}\text { Ailesel } \\
\text { Akdeniz Ateşi }\end{array}$ & $34,42 \pm 14,24$ & $22,84 \pm 19,72$ & $-33,6$ & $<0,001$ \\
\hline $\begin{array}{l}\text { Behçet } \\
\text { Hastalığ1 }\end{array}$ & $57,38 \pm 12,97$ & $63 \pm 15,17$ & 9,8 & 0,041 \\
\hline $\begin{array}{l}\text { Sistemik } \\
\text { Lupus } \\
\text { Eritematosus }\end{array}$ & $27,48 \pm 12,07$ & $23,13 \pm 17,09$ & $-15,8$ & 0,127 \\
\hline $\begin{array}{l}\text { Ankilozan } \\
\text { Spondilit }\end{array}$ & $60,69 \pm 17,77$ & $21,29 \pm 13,43$ & $-64,9$ & $<0,001$ \\
\hline $\begin{array}{l}\text { Romatoid } \\
\text { Artrit }\end{array}$ & $64,89 \pm 19,54$ & $50,71 \pm 18,58$ & $-21,8$ & $<0,001$ \\
\hline Osteoartrit & $43,06 \pm 20,35$ & $46,37 \pm 19,76$ & 7,7 & 0,373 \\
\hline $\begin{array}{l}\text { Sjögren } \\
\text { Sendromu }\end{array}$ & $47,57 \pm 24,29$ & $36,38 \pm 20,07$ & $-23,5$ & 0,012 \\
\hline Skleroderma & $32,21 \pm 24,56$ & $35,65 \pm 24,1$ & 10,7 & 0,493 \\
\hline
\end{tabular}

arama hacmi en fazla olan ilk beş romatizmal hastalığın gut, fibromiyalji, ailevi Akdeniz ateşi, Behçet hastalığı ve sistemik lupus eritematozus olduğu saptandı. Pandemi öncesi dönem ile karşılaştırıldığında, ailesel Akdeniz ateşi, ankilozan spondilit, romatoid artrit ve sjögren sendromu arama terimlerinin arama hacim ortalamaları istatistiksel olarak anlamlı derecede azalırken, Behçet hastalığı arama hacim ortalamasının ise arttığ1 tespit edildi.

Pandemi döneminde halkın sağlıkla ilgili bilgilere erişmek için internet kullanımının artması ve kamu eğilimlerinin araştırılması hastalıkların sıklığı hakkında ipuçları verebilir (27). Literatürde COVID-19 pandemisinde tıp disiplinleri tarafından çeşitli sağlık konularında kamunun ilgisi GT verileri ile değerlendirilerek sonuçlar bildirilmiştir. Çalışmalarda verilerin elde edildiği zaman aralıkları, seçilen sağlık konuları, karşılaştırma dönemleri, ülkelerin pandemiden etkilenme oranları ve aramaların yapıldığı ülkeler arasında farklılıklar olmasına rağmen COVID-19 pandemisinin ilk döneminde arama terimlerinin birçoğunda göreceli arama hacminde düşüş olduğu tespit edilmiştir (16-23). Dhanda ve ark. 1 Ocak 2020 ve 10 
Temmuz 2020 tarihleri arasında halkın fasiyal plastik cerrahi işlemlere ilgisini araştırdıkları çalışmalarında; Mart-Nisan 2020 döneminde, Ocak-Şubat 2020'ye kiyasla önemli bir düşüş olduğunu saptamıştır (17). Bhambhvani ve ark. elektif ürolojik işlemleri dört kategoriye ayırarak toplumun ilgisini GT verileri ile bildirdikleri araştırmalarında 18 Mart 2020'den önceki 30 gün içinde, 30 gün sonrasina kıyasla tüm kategorilerde ve Ocak 2015-Şubat 2020'ye kiyasla Mart-Mayıs 2020 döneminde bir düşüş olduğunu saptamıştır (18). Kardeş ve ark. COVID-19 pandemisi sırasında Amerika Birleşik Devletleri'nde romatizmal hastalıklara ve romatologlara halkın ilgisini GT verilerini kullanarak değerlendirdikleri çalışmalarında 15 Mart ile 9 Mayıs 2020 tarihleri arasında birçok romatizmal hastalık için önceki 4 yıldaki benzer dönemlere kıyasla göreli arama hacminde önemli bir azalma olduğunu; ilk dönem sona erdikten sonra eğilimlerin tersine döndüğünü bildirmiştir (19). Çalışmamızda pandemi öncesi dönem ile karşılaştırıldığında ailesel Akdeniz ateși, ankilozan spondilit, romatoid artrit ve sjögren sendromu göreli arama hacminde istatistiksel olarak anlamlı düşüş izlendi. Romatizmal hastalıklara kamu ilgisinin pandemi öncesi döneme göre azalması, COVID-19 ile romatolojik hastalıklar ve immünosupresif tedaviler arasında var olabilecek potansiyel riskler hakkında bilgi eksikliğiyle ilgili olabilir. Çalışmamızda Behçet hastalığı arama hacminin pandemi döneminde, pandemi öncesi dönem ile karşılaştıııldığında $\operatorname{arttığı~tespit~edildi.~} \mathrm{Bu}$ sonuç Türkiye'de Behçet hastalığının prevelansın yüksek olması, hastalığın özellikle 20-40 yaş arasında görülmesi ve bu yaş grubunda internet kullanımının yaygın olması ile ilişkili olabilir (28).

Romatizmal hastalıkları olan hastalarda sedanter yaşamın genel popülasyona göre daha yüksek olduğu bilinmektedir. Pandemi döneminde sosyal izolasyon ve karantina gerekliliği, virüs bulaşma ihtimaline karşı daha az fiziksel aktivite sedanter yaşamın artması ile sonuçlanmıştır. Fiziksel aktivitenin azlığı semptomları arttırıcı bir faktör olmuştur. Bu nedenle kronik ağrı, romatizmal hastalıkların aktivitesinin artması ve yaşam kalitesinin etkilenmesi çevrim içi arama verilerinde romatizmal hastalıkların aranmasında etkili olabilir (29).

GT verileri; kanser ilgisinin mevsimselliği, kanser taramasına ilgi ve farkındalık kampanyalarının etkinliği gibi birçok konuyu incelemek için kullanılmıştır. Çalışmamızda romatizmal hastalıklarla ile ilgili farkındalık günlerinin Google arama hacmindeki ani artışlara etkisi araştırılmıștı. Dijital ilginin en fazla olduğu romatizmal hastalıklar için lupus farkındalık günü (10 Mayıs), ailevi Akdeniz ateşi farkındalık günü (17 Eylül), fibromiyalji farkındalık günü (12 Mayıs), gut farkındalık günü (22 Mayıs) göreli arama hacmi incelendiğinde pandemi öncesi dönemde sadece ailesel Akdeniz ateşi terimi ile yapılan aramalarda ani artış olduğu saptandı. Pandemi döneminde ise farkındalık günlerinin göreli arama hacmindeki artışlara etkisinin olmadığı izlendi.

\section{Çalışmanın Kısıtııııkları}

Bazı lokasyonlarda internete sınırlı erişim, yaşlı hastalarda internet erişiminin daha az olabilmesi, arama yapan kişilerin demografik özelliklerinin tespit edilememesi, GT'nin gözlemsel sonuçlar sağlaması çalışmamızın kısıtlılıkları idi. Ayrıca çalışmanın diğer bir sınırlaması, Google arama motorunun analizi yapmak için kullanılan tek arama motoru olmasıdır. Ancak Türkiye'de 65,8 milyon $(\% 77,7)$ internet kullanıcısının olması ve en çok tercih edilen arama motorunun Google olması sebebiyle $(9,10)$ insanların bilgiye erişim için Google'a güvendiği, GT verilerinin Türkiye'yi temsil ettiği düşünülebilir.

\section{SONUÇ}

COVID-19 gibi pandemilerde çevrim içi internet arama sonuçlarının değerlendirilmesi hem halkın hastalıklara olan ilgisini ve eğilimlerini belirleme hem de toplumsal farkındalığın oluşturulabilmesi açısından önemlidir. Farkındalık günlerinin hastalıkların tanınmasında potansiyel faydalar sağlaması nedeniyle daha fazla vurgulanması gerektiğini düşünmekteyiz. Ayrıca gelecek nesillere bilgi teknolojisini "nasıl" kullanacaklarını öğretmeyi öğrenmeliyiz.

\section{Çıkar çakışması beyanı}

Yazarlar bu yazının hazırlanması ve yayınlanması aşamasında herhangi bir çıkar çakışması olmadığını beyan etmişlerdir.

\section{Finansman}

Yazarlar bu yazının araştırma ve yazarlık sürecinde herhangi bir finansal destek almadıklarını beyan etmişlerdir.

Yazar katkıları: Fikir/Kavram T.E.S., Tasarım T.E.S., Veri Toplama ve/veya İşleme T.E.S., Analiz ve/veya Yorum T.E.S., Literatür Taraması T.E.S., Makale Yazımı T.E.S, Eleştirel İnceleme S.A.

\section{KAYNAKLAR}

1. Zhu N, Zhang D, Wang W, Li X, Yang B, Song J, et al. A novel corona virüs from patients with pneumonia in China, 2019. N Engl J Med. 2020; 382(8): 727-33.

2. World Health Organization announces COVID-19 outbreak a pandemic. https://www.euro.who.int/en/health-

topics/healthemergencies/ coronavirus-covid19/news/news/2020/3/whoannounces-covid-19outbreak-a-pandemic/.Accessed 25 October 2021.

3. Demirbilek Y, Pehlivantürk G, Özgüler ZÖ, Alp Meşe E. COVID-19 outbreak control, example of ministry of health of Turkey. Turk J Med Sci. 2020; 50(SI-1): 489-94.

4. Sultanoğlu H, Boğan M, Erdem Sultanoğlu T, Altınsoy HB. Examination of physiological changes seen in workers using breathing masks during COVID-19 Pandemic. Hospital Practices and Research. 2021; 6(3): 93-7.

5. Sultanoğlu H. Düzce University Faculty of Medicine Department of Emergency Medicine and pandemic 
process. Konuralp Medical Journal. 2020; 12(S1): 372-3.

6. Ladani AP, Loganathan M, Danve A. Managing rheumatic diseases during COVID-19. Clin Rheumatol. 2020; 39(11): 3245-54.

7. Kastritis E, Kitas GD, Vassilopoulos D, Giannopoulos G, Dimopoulos MA, Sfikakis PP. Systemic autoimmune diseases, anti-rheumatic therapies, COVID-19 infection risk and patient outcomes. Rheumatology international. 2020; 40(9): 1353-60.

8. Sultanoğlu TE, Ataoğlu S. Düzce University Faculty of Medicine Department of Physical Medicine and Rehabilitation in the COVID-19 pandemic process. Konuralp Medical Journal. 2000;12(S1):386-7.

9. Datareportal.org [Internet]. Singapore: Digital 2021 Turkey; 2021 March 11 [ Updated: 2021 March 11; Cited: 2021 October 10]. Available from: https://datareportal.com/reports/digital-2021-turkey.

10. Statcounter Globalstats [Internet]. Ireland: SearchEngine-Market-Share Turkey; 2021 September 30[Updated: 2021 September 30; Cited: 2021 October 10].Available from: https://gs.statcounter.com/searchengine-market-share/all/turkey.

11. Brownstein JS, Freifeld CC, Madoff LC. Digital disease detection harnessing the Web for public health surveillance. The New England journal of medicine. 2009; 360(21): 2153-57.

12. Salathe M, Bengtsson L, Bodnar TJ, Brewer DD, Brownstein JS, Buckee C, et al. Digital epidemiology. PLoS computational biology. 2012; 8(7): e1002616.

13. Carneiro HA, Mylonakis E. Google trends: a webbased tool for real-time surveillance of disease outbreaks. Clin Infect Dis. 2009; 49(10): 1557-64.

14. Lu FS, Hou S, Baltrusaitis K, Shah M, Leskovec J, Hawkins J, Santillana M. Accurate influenza monitoring and forecasting using novel internet data streams: a case study in the Boston Metropolis. JMIR public health and surveillance. 2018; 4(1): e4.

15. Teng Y, Bi D, Xie G, Jin Y, Huang Y, Lin B, Tong Y. Dynamic forecasting of Zika epidemicusing Google Trends. PloSone. 2017; 12(1): e0165085.

16. Guzman AK, Barbieri JS. Analysis of dermatologyrelated search engine trends during the COVID-19 pandemic: Implications for patient demand for outpatient services and telehealth. J Am Acad Dermatol. 2020; 83(3): 963-5.

17. Dhanda AK, Leverant E, Leshchuk K, Paskhover B. A Google Trends analysis of facial plastic surgery interest during the COVID-19 pandemic. Aesthetic Plast Surg 2020; 44(4): 1378-80.

18. Bhambhvani HP, Tijerina JD, Parham MJ, Greenberg DR, Eisenberg ML. Public interest in elective urologic procedures in the COVID-19 pandemic: A Google Trends analysis. Urology Practice. 2020; 7(6): 496-501.

19. Kardeş S, Kuzu AS, Raiker R, Pakhchanian H, Karagülle M. Public interest in rheumatic diseases and rheumatologist in the United States during the COVID-19 pandemic: evidence from Google Trends. Rheumatology International. 2021; 41(2): 329-34.
20. Mavragani A, Ochoa G. Google Trends in infodemiology and infoveillance: methodology framework. JMIR public health and surveillance. 2019; 5(2): e13439.

21. Misitzis A, Weinstock MA. Increased interest in sunless tanning versus tanning beds in the United States: A Google Trends analysis. Journal of the American Academy of Dermatology. 2019; 81(6): 1438-9.

22. Landy DC, Chalmers BP, Utset-Ward TJ, Ast MP. Public interest in knee replacement fell during the onset of the COVID-19 pandemic: a Google Trends analysis. HSS Journal. 2020; 16(1): 24-8.

23. Pier MM, Pasick LJ, Benito DA, Alnouri G, Sataloff RT. Otolaryngology-related Google Search trends during the COVID-19 pandemic. Am J Otolaryngol. 2020; 41(6): 102615.

24. Google: Google Trends. Erişim: https://trends.google.com.tr/ Erişim tarihi: 01.10.2021

25. Yıldız MS. Google Arama Trendleri: Türkiye'de Sağlık Hizmetleri ile İlişkili Aramalar için Bir Uygulama. Uluslararası Sağlık Yönetimi Ve Stratejileri Araştırma Dergisi. 2018; 4(2): 168-79.

26. Akkoç N. Türkiye'de romatizmal hastalıkların epidemiyolojisi ve diğer ülkelerle karşılaştırılması. J Turk Soc Rheumatol. 2010; 2(2): 1-8.

27. Ciaffi J, Meliconi R, Landini MP, Ursini F. Google trends and COVID-19 in Italy: could we brace for impact? Internal and Emergency Medicine. 2020; 15(1): 1555-9.

28. Çölgeçen E, Özyurt K, Ferahbaş A, Borlu M, Kulluk P, Öztürk A, et al. The prevalence of Behçet's disease in a city in Central Anatolia in Turkey. International Journal of Dermatology. 2015; 54(3): 286-9.

29. Pinto AJ, Dunstan DW, Owen N, Bonfá E, Gualano B. Combating physical inactivity during the COVID19 pandemic. Nature Reviews Rheumatology. 2020; 16(7): 347-8. 